\title{
How to Interpret a Functional or Motility Test - Defecography
}

\author{
Ah Young Kim \\ Department of Radiology and Research Institute of Radiology, University of Ulsan College of Medicine, Asan Medical Center, Seoul, Korea
}

Defecography evaluates in real time the morphology of rectum and anal canal in a physiologic setting by injection of a thick barium paste into the rectum and its subsequent evacuation. Because of its ability of structural and functional evaluation, defecography is primarily performed for work up of patients with longstanding constipation, unexplained anal or rectal pain, residual sensation after defecation or suspected prolapse. Technique and interpretation of this examination are outlined in this review.

(J Neurogastroenterol Motil 2011;17:416-420)

Key Words

Constipation; Defecation; Defecography; Pelvic floor

\section{Introduction}

Defecography, also referred to as evacuation proctography or voiding proctography, has been established as a particularly useful fluoroscopic examination for patients with defecation difficulties because it enables a functional, real-time assessment of the defecation mechanics in a physiologic setting. Despite recent advances in magnetic resonance (MR) defecography, this technique still represents a widely available and cost-effective diagnostic tool. $^{1-6}$

\section{Principle of Defecography}

\section{Patient Preparation}

Preparation of the bowel with laxatives or enemas is not necessary. In some institutes, however, the patient can undertake a rectal cleansing enema at home a few hours before the examination because a limited bowel preparation will be more comfortable for the patient and will also provide a more standardized examination.

Before the procedure, it is very important to obtain a complete clinical history with particular attention to abdominal and pelvic surgery, clinical conditions (such as diabetes, hypothyroidism and systemic disorders) and drug consumption. Other clinical history should be recorded as follows; the period of dyschezia, the frequency of defecation per week, the time required for usual defecation, the sense of tenesmus or incomplete evacuation, the specific pose during defecation and the use of specific maneuver (digitalization)/laxative/enema.

To perform a correct examination, collaboration of the patient is essential. The entire procedure should be explained to the patient so that the patient follows actual instructions of the exami-

Received: September 7, 2011 Revised: September 14, 2011 Accepted: September 16, 2011

(c) This is an Open Access article distributed under the terms of the Creative Commons Attribution Non-Commercial License (http://creativecommons. org/licenses/by-nc/3.0) which permits unrestricted non-commercial use, distribution, and reproduction in any medium, provided the original work is properly cited.

*Correspondence: Ah Young Kim, MD

Department of Radiology and Research Institute of Radiology, University of Ulsan College of Medicine, Asan Medical Center, 388-1

Poongnap 2-dong, Songpa-gu, Seoul 138-040, Korea

Financial support: None.

Tel: +82-2-3010-4400, Fax: +82-2-3010-8570, E-mail: aykim@amc.seoul.kr

Conflicts of interest: None. 
nation correctly in a relaxed and comfortable condition.

\section{Opacification of Vagina and/or Small Intes- tine}

In female patients, the vagina is usually opacified with a commercially available barium sulfate for oral use. Various agents such as water-soluble contrast agent or radiopaque gel are also used for vaginal opacification.

To diagnose enterocele, the small bowel should be opacified with the same barium used for examination of the small intestine. Oral ingestion of 400 to $600 \mathrm{~mL}$ barium suspension is given 45 to 60 minutes before the fluoroscopic study. Sometimes, it may take up to 3 hours for ingested oral contrast to reach pelvic ileal loops.

\section{Rectal Opacification and Defecation}

At the beginning of examination, about 250 to $300 \mathrm{~mL}$ of thick barium paste is injected into the rectum on left lateral decubitus position. To keep the appropriate consistency similar to stool, commercial formulations or a barium paste prepared with barium and potato starch can be used for rectal opacification. Injection of the barium paste is usually done by a regular caulking gun. When the patient reaches the stimulus to evacuate, the anal bulb is completely filled and injection can be interrupted.

And then, the fluoroscopic table is tilted vertically and a special commode is attached to the footboard. The patient is asked to sit on the commode in right lateral projection. When the radiogenic tube is correctly centered on the pelvis, the first radiograph (scout film) is obtained. In general, the entire examination should be recorded through videofluoroscopy with several spot filming of key events. Spot radiographs are obtained in the lateral position with the patient responding to requests to rest, squeeze, strain and defecation. The patient must be instructed to empty the rectum completely. Finally, post-evacuation spot radiograph is also obtained after full evacuation. Without interruption, this process takes less than 30 seconds in physiologic conditions. ${ }^{7}$

\section{Interpretation of Defecography}

\section{Parameters}

The anorectal angle (ARA) is measured between the longitudinal axis of anal canal and the posterior rectal line, parallel to the longitudinal axis of the rectum (Fig. 1). It can be difficult to measure because the posterior wall of the rectum is often not clearly delineated and the angle becomes highly subjective. ${ }^{8}$ At rest, its average value is $95-96^{\circ}$ (physiologic range, $65-100^{\circ}$ ) without noticeable differences between men and women. ${ }^{7,9,10}$ ARA is an indirect indicator of the puborectal muscle activity. During muscle contraction, ARA becomes more acute, while during relaxing phase it becomes obtuse.

The second important parameter for evaluation is the shift of the anorectal junction (ARJ) during straining. ARJ is the uppermost point of the anal canal. The line drawn between the ischial tuberosities is called the bis-ischiatic line and can be used as a fixed bony landmark. Another fixed reference point is represented by the tip of the coccyx. The craniocaudal migration of ARJ indirectly represents the elevation and descent of pelvic floor. The reproducibility and reliability of these 2 parameters as usually measured have been confirmed, but their clinical significance is still controversial. ${ }^{7}$

\section{Normal Findings}

In the resting phase (Fig. 2A), the impression of puborectal sling is visible on the posterior wall of caudal rectum and the ARA is about $90^{\circ}$. During voluntary contraction of the pelvic floor (squeezing) (Fig. 2B), the ARA decreases to about $75^{\circ}$ and the ARJ migrates cranially. The puborectal impression becomes more evident because of the contraction of levator ani.

While the patient is asked to strain (Fig. 2C), the ARA in-

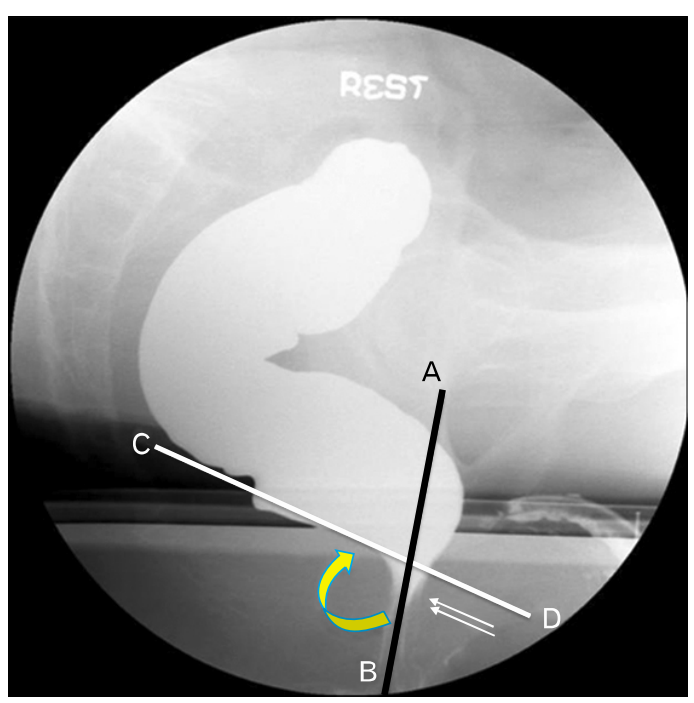

Figure 1. Measurement of anorectal angle. Anorectal angle (curved arrow) is measured between the longitudinal axis of anal canal (AB) and the posterior rectum line parallel to the rectum longitudinal axis (CD). Double thin arrows show the position of the anorectal junction. 

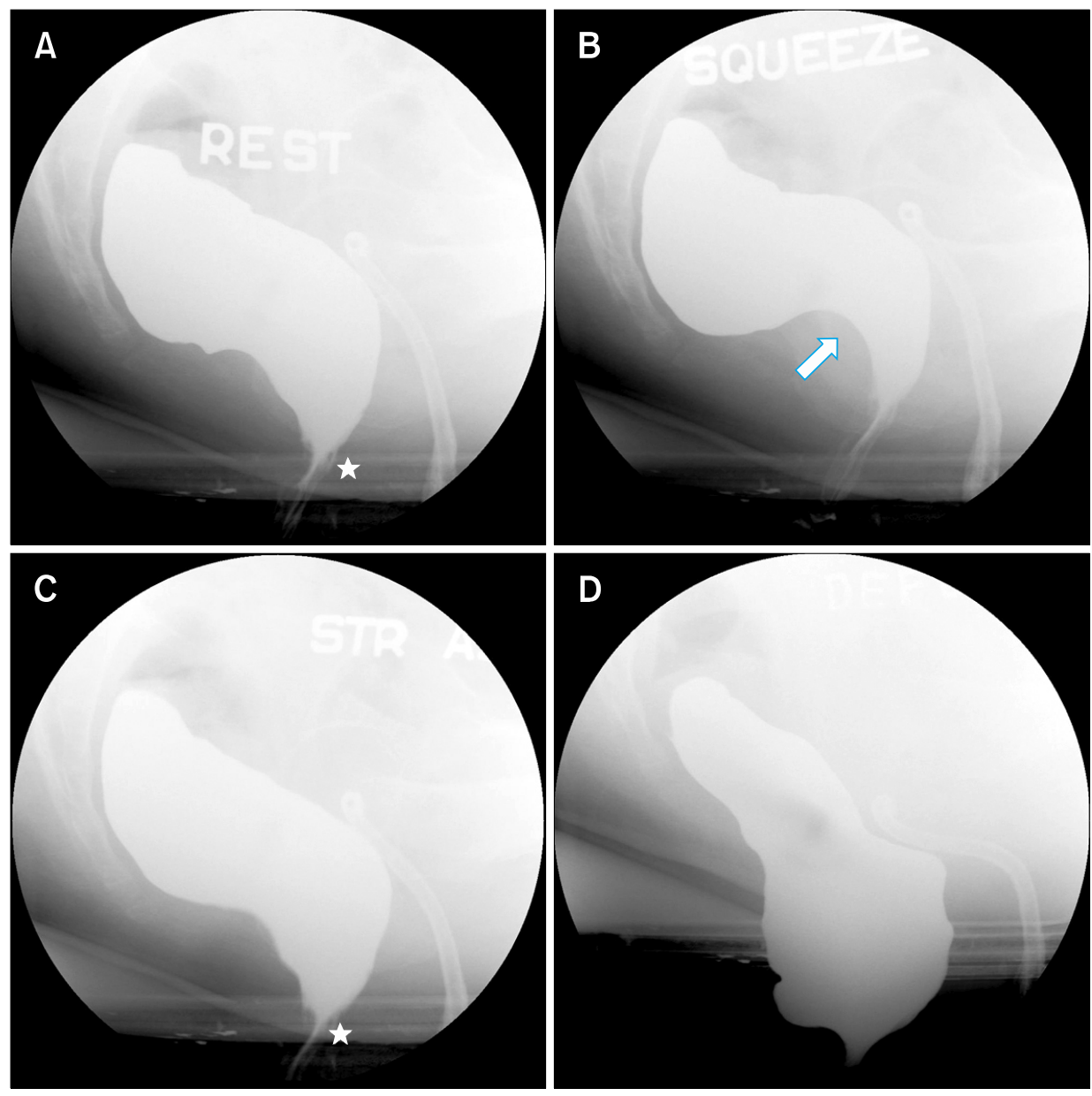

Figure 2. Normal defecography. At rest (A). Note the deeper impression exerted by the puborectal sling (arrow) and the cranial migration of the distal rectum during forced contraction (B). During straining with closed sphincters (C), caudal migration of the anorectal junction is seen (asterisk). During evacuation (D), the anal canal opens with loss of puborectalis impression.

creases with partial to complete loss of puborectal impression and the pelvic floor descends. The degree of caudal migration of ARJ is considered normal when less than $3.5 \mathrm{~cm}$ relative to the resting position. ${ }^{11}$

During evacuation (Fig. 2D), wide opening of the anal canal and funneling of the anorectum are seen with near complete loss of puborectal sling impression. The ARA increases with the relaxation of anal sphincter and puborectalis muscle. At the end of evacuation, the rectum is completely empty and its walls collapse. Eventually, the rectum is restored to its original resting condition.

\section{Dyskinetic Puborectlis Muscle Syndrome}

Also known as spastic pelvic floor syndrome, this condition is due to an inappropriate contraction of pelvic floor during defecation. Characteristic findings of defecography include a lack of pelvic floor descent and paradoxical contraction of the puborectalis muscle. Another less specific feature is an aberrantly deep im- pression of the puborectalis sling on the posterior rectal wall at rest (Fig. 3). This is caused by the presence of a hypertrophic puborectalis muscle. But, this finding is also seen in some normal individuals. $^{12}$

Prolonged and incomplete evacuation during defecography are the specific findings of this syndrome. Evacuation time longer than 30 seconds is highly predictive of dyskinetic puborectalis muscle syndrome, having a positive predictive value of $90 \% .^{13}$

\section{Intussusception and Rectal Prolapse}

Rectal intussusception is a concentric invagination of the entire rectal wall during straining or defecation. It may be classified as intra-rectal, intra-anal or total rectal prolapse (where the rectum passes through the anal canal). It usually begins at 6 to $8 \mathrm{~cm}$ above the anal canal as an invagination of one of the valves of Houston. ${ }^{11}$ At defecography, the presence of transverse or oblique infolding of the rectal wall of more than $3 \mathrm{~mm}$ thickness, which is presented as a funnel or ring-like configuration during 


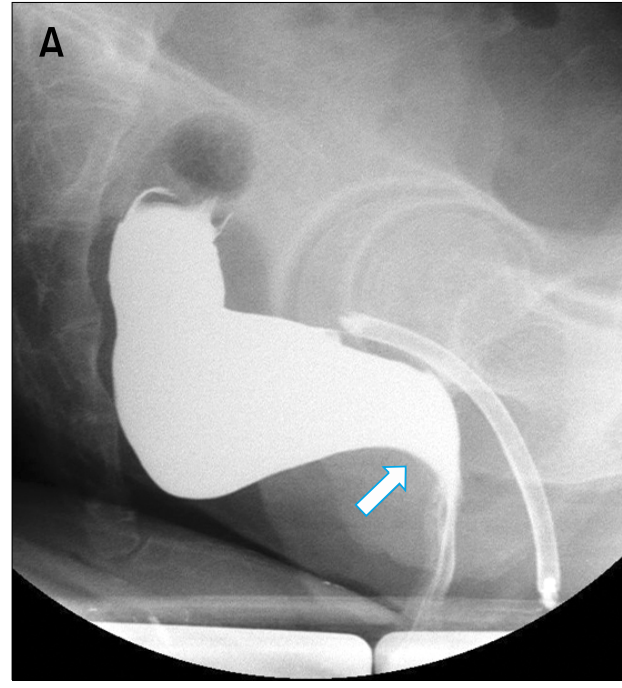

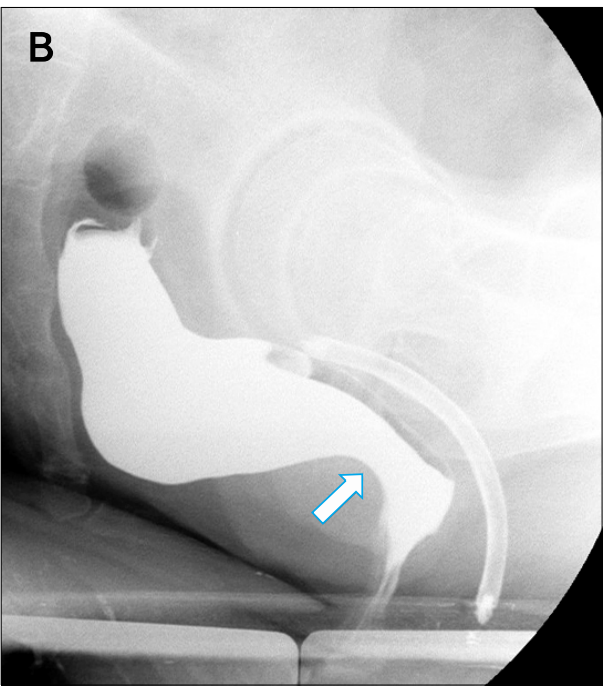

Figure 3. Dyskinetic puborectalis muscle syndrome. Note abnormally deep puborectal impression (arrow) at rest (A) and at evacuation phase (B). During evacuation phase, there is lack of pelvic floor descent. straining, represents intussusception. Minor degrees of infolding of less than $3 \mathrm{~mm}$ thickness represent mucosal prolapse and are probably not significant. In complete rectal prolapse, dilatation of the anal canal is evident during evacuation, and a circular infolding of the rectal wall invaginates into the lumen. Descent can be so dramatic as to pass through the anus and prolapsed externally.

\section{Rectocele}

Rectocele is an anterior bulge of the rectal wall wider than 2 $\mathrm{cm}$ in the anteroposterior diameter. ${ }^{6}$ This condition is more commonly found in females because of the laxity of rectovaginal septum. Outpouchings smaller than $2 \mathrm{~cm}$ are frequently found in asymptomatic females. ${ }^{9}$

On defecography, an anterior outpouching of the anterior rectal wall bulges and dislocates the opacified vaginal lumen during straining and evacuation. A rectocele does not necessarily impede evacuation but retention of stool within a rectocele may lead to a sense of incomplete evaluation and the need for digital maneuver to complete evacuation.

\section{Enteroceles and Sigmoidoceles}

Peritoneal sac herniations are demonstrated most frequently at the end of evacuation and can be filled with small bowel (enterocele) or sigmoid colon (sigmoidocele). They result from the herniation of the peritoneal sac into the rectovaginal space. On defecography, descent of barium-filled ileal loops is evident during evacuation in the space between the rectum and vagina that is widened. Widening of this space or the presence of air in this space is also an indirect sign of enterocele when opacification of ileal loops is not achieved.

\section{Descending Perineum Syndrome}

Excessive pelvic floor descent during defecation is often caused by pudendal nerve injury resulting from a combination of obstetric trauma and chronic straining. The main radiographic feature is the caudal migration of the anorectal junction more than $3.5 \mathrm{~cm}$ during straining. The anorectal angle is more than $130^{\circ}$ at rest and increases to more than $155^{\circ}$ during straining. ${ }^{14-16}$ Incontinence is frequently associated with this syndrome.

\section{Conclusion}

Defecography is a reliable and reproducible technique as well as a cost-effective and easy-assessable procedure for evaluation of defecation disorders. Although the condition is complex with overlap of imaging findings between normal and symptomatic individuals, this method has the highest accuracy in diagnosing rectal intussusception, prolapse and enterocele. The main limitation of this technique is patient's exposure to ionizing radiation in comparison with MR defecography, while MR defecography is limited in availability. Defecography still represents a unique diagnostic technique for the examination of defecation dysfunctions.

\section{References}

1. Brodén B, Snellman B. Procidentia of the rectum studied with cineradiography. A contribution to the discussion of causative mechanism. Dis Colon Rectum 1968;11:330-347.

2. Mahieu PH, Pringot J, Bodart P. Defecography: I. Description of a 
new procedure and results in normal patients. Gastrointest Radiol 1984;9:247-251.

3. Mahieu PH, Pringot J, Bodart P. Defecograph: II. Contribution to the diagnosis of defection disorders. Gastrointest Radiol 1984;9:253261.

4. Ganeshan A, Anderson EM, Upponi S, et al. Imaging of obstructed defecation. Clin Radiol 2008;63:18-26.

5. Roos JE, Weishaupt D, Wildermuth S, Willmann JK, Marincek B, Hilfiker PR. Experience of 4 years with open MR defecography: pictorial review of anorectal anatomy and disease. Radiographics 2002;22:817-832.

6. Mezwa DG, Feczko PJ, Bosanko C. Radiologic evaluation of constipation and anorectal disorders. Radiol Clin North Am 1993;31: 1375-1393.

7. Choi JS, Wexner SD, Nam YS, et al. Intraobserver and interobserver measurements of the anorectal angle and perineal descent in defecography. Dis Colon Rectum 2000;43:1121-1126.

8. Penninckx F, Debruyne C, Lestar B, Kerremans R. Observer variation in the radiological measurement of the anorectal angle. Int $\mathrm{J}$ Colorectal Dis 1990;5:94-97.

9. Shorvon PJ, McHugh S, Diamant NE, Somers S, Stevenson GW.
Defecography in normal volunteers: results and implications. Gut 1989;30:1737-1749.

10. Pieri L, Perri G, Napoli V, Falaschi, Iacconi P. [Digital videoradiography applied to the study of the recto-anal region during defecography.] Radiol Med 1991;81:90-96. [Italian]

11. Karasick S, Karasick D, Karasick SR. Functional disorders of the anus and rectum: findings on defecography. AJR Am J Roentgenol 1993;160:777-782.

12. Halligan S, Bartram CI, Park HJ, Kamm MA. Proctographic features of anismus. Radiology 1995;197:679-682.

13. Halligan S, Malouf A, Bartram CI, Marshall M, Hollings N, Kamm MA. Predictive value of impaired evacuation at proctography in diagnosing anismus. AJR Am J Roentgenol 2001;177:633-636.

14. Kuijpers HC, Schreve RH, ten Cate Hoedemakers H. Diagnosis of functional disorders of defecation causing the solitary rectal ulcer syndrome. Dis Colon Rectum 1986;29:126-129.

15. Ekberg O, Nylander G, Fork FT. Defecography. Radiology 1985; 155:45-48.

16. Yang XM, Partanen K, Farin P, Soimakallio S. Defecography. Acta Radiol 1995;36:460-468. 